\title{
Letter from the editor
}

\author{
Sung Deuk Hahm
}

Published online: 23 June 2013

(c) Korean Social Science Research Council 2013

I am very pleased to announce that the Korean Social Science Research Council (KOSSREC) will collaborate with the Springer Publishing company to publish the Korean Social Science Journal (KSSJ) from this issue forward by the standards of the social science citation index (SSCI) journal. To pursue and achieve our goal, we are determined that the KOSSREC and Springer will publish two KSSJ issues annually, broaden awareness of the KSSJ among social science scholars, increase the number of manuscript submissions, and enhance the quality of manuscripts received. Most importantly, through this collaboration, we expect that the KSSJ will be accepted into the SSCI in no time at all. We believe that this is a major step toward making the $K S S J$ become the premier journal in social science we aim for it to be.

To this end, I am pleased to present our premier issue filled with articles on a wide range of social science topics that meet the excellence to which we aspire, articles such as "Rising Earnings Inequality and the Role of Education Revisited," "The Political Economy of U.S. Economic Performance: Is the President Responsible?," and "Peaceful Power Transfers or Successions and Democratic Consolidation in South Korea."

Finally, I would like to thank the people who served as referees for the KSSJ during the first half of 2013. No scholarly journal can exist without the generous service of its referees, and we are particularly lucky to have had so many who have provided very useful comments to our prospective authors. Great referees are, I think, one of the advantages that the $K S S J$ offers to those choosing to submit papers to us.

Sung Deuk Hahm

Editor-in-Chief

S. D. Hahm (ه)

Korea University, Seoul, South Korea

e-mail: hahm33@hotmail.com 